\title{
Gertrudis Gómez de Avellaneda entre Cuba e Espanha relatos de viagem e ambivalências em torno da questão da identidade nacional*
}

\author{
Gertrudis Gómez de Avellaneda \\ between Cuba and Spain \\ travel narratives and questions of ambivalence \\ surrounding national identity**
}

\author{
Stella maRis SCATENA FRANCO \\ Professora Adjunta do Departamento de Artes e Humanidades \\ da Universidade Federal de Viçosa \\ Doutora em História Social pela Universidade de São Paulo \\ stellafv@ufv.br
}

RESUMO Este artigo analisa relatos de viagem de Gertrudis Gómez de Avellaneda, escritora cubana do século XIX, procurando mostrar as ambivalências presentes em seu discurso no que diz respeito à questão da identidade nacional. Além disso, pretende apresentar as polêmicas a respeito de sua inserção nos cânones literários cubano e espanhol. Tais questões vinculam-se a aspectos históricos atinentes à peculiar situação política

\footnotetext{
* Artigo recebido em 15/06/2007. Autora convidada.

** Este artigo é escrito a partir de minha Tese de Doutorado, Peregrinas de outrora: viajantes latino-americanas no século XIX, defendida junto ao Programa de Pós-Graduação em História Social da USP, em 2005, na qual estudei os relatos de viagem à Europa e Estados Unidos produzidos por três escritoras latino-americanas: a cubana Gertrudis Gómez de Avellaneda, a argentina Eduarda Mansilla de García e a brasileira Nísia Floresta. Na tese. procurei analisar, dentre outros aspectos, a forma como as viajantes representaram o chamado "mundo civilizado", além de abordar as questões de gênero, refletindo sobre a maneira como as autoras compreendiam os papéis sociais femininos.
} 
de Cuba enquanto uma das últimas possessões coloniais da Espanha no continente americano.

Palavras-chave identidade, relatos de viagem, Cuba, Gertrudis Gómez de Avellaneda

ABSTRACT This article analises the travel writings of Gertrudis Gómez de Avellaneda, Cuban writer of the $19^{\text {th }}$ century, trying to show the present ambivalences in her speech concerning to the national identity subject. Furthermore, it aims to present the polemics around her insertion in the Cuban and Spanish literary canons. Such subjects are linked to historical aspects related to the political peculiar situation of Cuba while one of the last colonial possessions of Spain in the American continent.

Key words identity, travel writings, Cuba, Gertrudis Gómez de Avellaneda

A escritora Gertrudis Gómez de Avellaneda (1814-1873) nasceu em Cuba e viveu muitos anos na Espanha. A mudança de Cuba colonial para a metrópole marcou sua trajetória. Tendo vivido e construído sua carreira literária na Espanha, foi acusada, em Cuba, de ter "traído suas origens", acusação que chegou a negar veementemente. Salientamos, deste modo, a particular situação desta personagem, colocada em meio a dois pólos diferenciados e, até certo ponto, antagônicos. Neste artigo, apresentamos esta polêmica em torno da escritora e pretendemos mostrar, por meio da leitura de seus relatos de viagem, a presença de ambivalências em seu discurso no que diz respeito à questão de sua identidade enquanto "espanhola" ou "cubana".

Para iniciar, cabe apontar brevemente aspectos relativos à vida e obra da autora. Era filha de um militar espanhol e sua mãe pertencia a uma abastada família criolla de Camagüey, porção oriental da ilha. Ainda na infância ficou órfã de pai, tenho sua mãe se casado novamente com outro espanhol. Muito jovem fora prometida em casamento a um parente distante, de elevada condição social, compromisso a que se negou. Este ato de insubordinação teria comprometido o recebimento da herança de seu avô materno. Em 1836 partiu com a família de mudança para a Espanha. Encontramos mais de uma justificativa para esta mudança. Em textos autobiográficos, a autora afirma que a motivação da viagem era retomar um antigo sonho do pai, que morrera frustrado por não retornar à sua terra 
natal. ${ }^{1}$ Por outro lado, também mostra haver, por parte de sua família, uma inquietação com relação à situação política da ilha, sobretudo no que se refere à escravidão; ainda mais sendo, eles próprios, proprietários de escravos. ${ }^{2}$ Sua família temia que se desenrolasse em Cuba uma rebelião de escravos nas proporções da que tinha ocorrido no Haiti. Alude-se ainda ao fato de que a mudança poderia estar relacionada ao episódio do rechaço, pela autora, do compromisso matrimonial estipulado pela família. ${ }^{3}$

Depois de dois anos viajando pela Espanha, França e Portugal, passou a morar em Sevilha e, logo, em Madri. Sua carreira literária se desenvolverá fortemente a partir da década de 1840. Em 1841 publicou seu romance mais conhecido e estudado. Trata-se de Sab, ambientado em Cuba e que descreve uma paixão não correspondida, desenvolvida por um escravo mulato em relação a sua senhora. ${ }^{4} \mathrm{O}$ romance faz fortes ataques à escravidão e associa a condição do escravo à da mulher, no que diz respeito à falta de liberdade desses dois grupos sociais. Avellaneda destaca-se também por sua produção poética, mas sobretudo por suas peças de teatro, que foram encenadas em Madri, contando muitas vezes com a presença de personagens da corte. Redigiu uma grande quantidade de cartas, além de textos biográficos e dois relatos de viagem, escritos com uma diferença de pouco mais de duas décadas. O primeiro, um relato em forma epistolar, ${ }^{5}$ narra seus dois primeiros anos na Europa (1836-38) e o segundo ${ }^{6}$ descreve uma viagem aos Pirineus, realizada com seu segundo marido, em 1859. ${ }^{7}$ Logo após esta segunda viagem, voltou para Cuba depois de muito tempo de ter de lá partido. O retorno se deu em razão de seu marido ter sido designado para ocupar um posto político na ilha. Com sua morte, em 1864, Avellaneda, retornou à Espanha e ali viveu até o fim de seus dias.

Da ampla gama de textos produzidos pela autora, detemo-nos, neste artigo, mais pontualmente em seus dois relatos de viagem.

1 GÓMEZ DE AVELLANEDA, Gertrudis. Autobiografia y cartas (hasta ahora inéditas) de la ilustre poetisa Gertrudis Gómez de Avellaneda. $2^{\mathrm{a}}$.ed. Madrid: Imprenta Helenica, 1914

2 Em sua autobiografia afirma que diante da decisão da mudança, seu padrasto vendeu os escravos e mandou o dinheiro para a Europa. GÓMEZ DE AVELLANEDA, Gertrudis. Autobiografia y cartas (hasta ahora inéditas) de la ilustre poetisa Gertrudis Gómez de Avellaneda.

3 COTARELO Y MORI, Emilio. La Avellaneda y sus obras. Ensayo biográfico y crítico. Madrid: Tipografía de Archivos, 1930.

4 GÓMEZ DE AVELLANEDA, Gertrudis. Sab. La Habana: Editorial Arte y Cultura, 1976.

5 GÓMEZ DE AVELLANEDA, Gertrudis. Memorias inéditas de la Avellaneda. Epistolario a su prima Eloisa Arteaga y Loinaz. La Habana: Imprenta de la Biblioteca Nacional, 1914

6 GÓMEZ DE AVELLANEDA, Gertrudis. Mi última excursión por los Pirineos.In: Obras. Tomo VI (Miscelánea). La Habana: Imprenta de Aurelio Miranda, 1914. Originalmente publicada em forma de folhetim, no Diário de la Marina, de Havana, de 20 de junho a 28 de julho de 1860.

7 Avellaneda teve uma vida emocional conturbada. Após romper o compromisso familiar de casamento com um rico parente, envolveu-se diversas vezes em relacionamentos frustrados. Manteve durante muito tempo uma paixão candente por um advogado espanhol, Ignácio de Cepeda, não sendo correspondida. Envolveu-se com um poeta espanhol, Gabriel Tassara, com quem teve uma filha não reconhecida pelo pai e que morreu precocemente. Depois, já mais madura, casou-se com um homem bem mais velho do que ela e influente na política espanhola, Pedro de Sabater, governador civil de Madri. Três meses depois do casamento ele faleceu. Depois, uniu-se em segundo matrimônio a Domingo Verdugo, militar espanhol. 
Gertrudis Gómez de Avellaneda chegou à Europa em 1836, aos 22 anos de idade. Fixou residência na Espanha e ali viveu outros 23 anos antes de retornar a Cuba, em 1859. A produção de seus dois relatos de viagem coincide com estes momentos particulares de sua vida. O primeiro, suas memórias epistolares, escritas em 1838 e endereçadas a uma prima cubana, retrata a partida do país natal e os dois primeiros anos na Europa, passando por Bordéus, Lisboa, regiões da Galícia e da Andaluzia, até fixar-se em Sevilha. O segundo, narra uma viagem pelos Pirineus, realizada meses antes de voltar a Cuba, em fins de 1859, tendo sido publicado em Havana, no ano seguinte.

A autora elaborou poeticamente tanto sua partida como seu retorno a Cuba. Em Al Partir, escrito quando deixava a ilha, lê-se: "iAdiós, patria feliz, edén querido!/iDoquier que el hado en su furor me impela,/tu dulce nombre halagará mi oído!". ${ }^{8}$

O crítico cubano Severo Sarduy destaca o sentido sonoro do soneto. Para ele, mais do que como uma imagem, o poema se apresenta como um "som": "lo que significa a Cuba, lo que la representa y contiene, como a una perla marina engarzada o a una estrella en el cielo occidental, es su nombre". ${ }^{9}$ Com isto, quer nos dizer que, ao cantar poeticamente Cuba, Avellaneda atribuía-lhe um sentido específico, uma existência única que passava a se auto-traduzir pelo seu próprio nome. Al Partir, assim, ganha uma aura de hino a Cuba. Além disso, o soneto evoca a "tradição do exílio", sobre a qual o crítico literário Enrico Mario Santí faz menção em um de seus ensaios, ao analisar as idéias de intelectuais cubanos do século XIX e evidenciar, desde inícios deste século, a presença, na literatura insular, de "una identidade cubana consciente de sí misma". ${ }^{10}$ Para o autor, boa parte dos intelectuais do século XIX viveu a experiência do exílio e contribuiu para forjar a identidade cubana a partir do estrangeiro: "Cuba se inventó a si misma en el siglo XIX, pero lo hizo pagando un legado de exilio", como o demonstram as trajetórias de Félix Varela, José María Heredia, José Antonio Saco e, mais tarde, José Martí; e, além deles, Avellaneda que, segundo o autor, criou o "prototípico poema del exilio: Al Partir". ${ }^{11}$

A poetisa também registrou seu retorno a Cuba, em 1859, com um soneto, intitulado La vuelta a la Patria. Ainda que menos popular, esta saudação,

8 GÓMEZ DE AVELLANEDA, Gertrudis. Al Partir. In: Antologia (poesias y cartas amorosas). (Prólogo y edición de Ramón Gómez de la Serna). 2ª ed. Buenos Aires; México: Espasa-Calpe Argentina 1948.

9 SARDUY, Severo. Tu dulce nombre halagará mi oído. Citado por MÉNDEZ-RODENAS, Adriana. Mujer, nación, y otredad en Gertrudis Gómez de Avellaneda. In: Cuba en su imagen: historia e identidad en la literatura cubana. Madrid: Editora Verbum, 2002, p.29.

10 SANTÍ, Enrico Mario. Nación inventada. In: Bienes del siglo: sobre cultura cubana. México: Fondo de Cultura Económica, 2002, p.21-22

11 SANTí, Enrico Mario. Nación inventada, p.33. 
na apreciação de Adriana Méndez-Rodenas, "restituye el vacío del exilio por la hechura poética con que registra el anhelado retorno al suelo natal". ${ }^{2}$

Com poucos anos de residência na Espanha, Avellaneda escreveu uma biografia de sua conterrânea, Maria de las Mercedes Santa-Cruz y Montalvo, a condessa de Merlin, inserida como prólogo de Viaje a La Habana, da condessa, publicado em Madri, em 1844. ${ }^{13}$ Neste prólogo, Avellaneda destaca a condição da condessa, bem como a de Heredia, como escritores que produziram suas obras longe da pátria, ao mesmo tempo em que sustenta, apesar do desterro, a permanência de vínculos com Cuba:

Desgracia es de Cuba que no florezcan en su suelo muchos de los aventajados ingenios que sabe producir. Heredia vivió y murió desterrado, y apenas llegaron furtivamente a sus compatriotas los inspirados tonos de su lira. La señora Merlin escribe en un país extranjero y en una lengua extranjera, como si favoreciesen diferentes circunstancias la fatalidad que despoja a la reina de las antillas de sus más esclarecidos hijos. Sin embargo, aquellas glorias trasplantadas a extrañas regiones no son por cierto inútiles a la patria: no son por cierto ingratas al cielo privilegiado que les dio vida. ${ }^{14}$

Além disso, Avellaneda comparou sua trajetória à da condessa e refletiu sobre a experiência do exílio e sobre sua condição de "estrangeira", afirmando:

\begin{abstract}
Existencia sin comienzo, espetáculo sin interés, detrás de sí unos días que nada tienen que ver con lo presente, delante otros que no encuentran apoyo en lo pasado, los recuerdos y las esperanzas divididos por un abismo, tal es la suerte del desterrado. (...) Así como en las familias hay lazos de unión, entre los que comenzaron la vida bajo un mismo cielo hay simpatías que en vano se quisieran destruir: hay unos mismos hábitos, y con corta diferencia una misma manera de ver y de sentir. Es fácil hacerse comprender por aquelles de quienes es un largo tiempo conocido; pero el extranjero necesita explicarse. Faltan la ternura que adivina y la costumbre que enseña. El extranjero es interpretado antes de ser conocido. ${ }^{15}$
\end{abstract}

12 MÉNDEZ-RODENAS, Adriana. Mujer, nación, y otredad en Gertrudis Gómez de Avellaneda. In: Cuba en su imagen historia e identidad en la literatura cubana. Madrid: Editora Verbum, 2002, p.15.

13 Mercedes Montalvo, a Condessa de Merlin, nasceu em 1789, no seio da aristocracia de Havana, possuindo seus pais título de nobreza. Aos 13 anos de idade, mudou-se para Madri e, posteriormente, fixou residência em Paris, onde publicou suas obras e manteve um salão literário que recebia personalidades do mundo cultural francês, como Victor Hugo, Georges Sand, Lamartine, e intelectuais cubanos, como José Antonio Saco e Domingo Delmonte. Em 1840, viajou para Havana, experiência na qual se baseou para escrever relatos sobre a ilha. Em 1844, além do Viaje a La Habana, com prólogo de Avellaneda, saía na França uma versão muito mais extensa, composta de três volumes, sobre sua viagem, intitulada La Havane. Morreu em Paris, em 1852. Para uma análise da autora, ver: MÉNDEZ-RODENAS, Adriana. 'Las mugeres de La Habana': una polémica feminista en el romanticismo hispanoamericano. In: Cuba en su imagen: historia e identidad en la literatura cubana. Madrid: Editora Verbum, 2002, p.15

14 GÓMEZ DE AVELLANEDA, Gertrudis. Apuntes biográficos de la Condesa de Merlin. In: Viaje a La Habana por la Condesa de Merlín. Madrid: [s.n.], 1844.

15 GÓMEZ DE AVELLANEDA, Gertrudis. Apuntes biográficos de la Condesa de Merlin, p.13-14. 
A temática do desterro está presente também em seu primeiro relato de viagem, escrito pouco tempo depois de deixar as plagas natais. Não nos parece circunstancial o fato dos versos de Heredia, poeta para quem a experiência do exílio fora marcante, e por quem a autora nutria grande inspiração, antecederem o primeiro dos quatro "cuadernillos" de seu relato. A epígrafe traduz a idéia de que a felicidade só se concretiza na terra pátria, nunca no estrangeiro: "Feliz, Elpino, el que jamás conoce/Otro cielo ni sol que el de su patria!"16

No primeiro caderno, a autora narra sua partida de Cuba em direção à Europa, a travessia oceânica até a chegada ao porto francês de Pauillac, além dos 18 dias passados em Bordéus. Ao relatar a partida, assinala a tristeza e a dor da despedida da terra natal: "[dejaba] enteramente detrás la isla de Cuba, y sofocando el ruído de las olas los últimos adioses que dirigiera en mi dolor á aquella tierra querida". ${ }^{17}$ Versos finais de uma canção que afirma ser entoada pelos marinheiros durante a travessia são reproduzidos por ela. Eles evocam a distância da terra natal: "Le beau pays de Normandie/C'est le pays qui m'a donné les jours". ${ }^{18}$ Para Avellaneda, esta "tonada lánguida y afectuosa" tinha algo de "triste y melancólico", melancolia que se associava à partida de Cuba. A letra da canção entoada pelos marinheiros, como referência à terra distante, desperta as lembranças de sua pátria, do passado nela vivido e, como que revivendo o drama de seu pai, mostra medo de não voltar a revê-la:

Cuántas veces, mientras la oia, entregábame yo también a los recuerdos de mi hermosa patria que acababa de abandonar tal vez para siempre! Pensaba en los dias tranquilos de mi infancia, en aquellos dias pasados en el seno del mejor y más querido de los padres; en los conocimientos y relaciones de mis primeros años, y en aquella época en que mi corazon me advirtió que habia cesado de ser niña. ${ }^{19}$

Ao longo do texto, outros exemplos refletem sua percepção de Cuba a partir de uma veia nostálgica. Ao iniciar o segundo "cuadernillo", em que narra os 20 meses passados em La Coruña, onde morava a família de seu padrasto, recorda sua infância em Cuba e a retrata como um paraíso perdido, no qual predominavam uma inocência e um mundo de ilusões, que as novas experiências não conseguiam preencher:

Que no estuviera yo ahora sentada en la puerta de tu casa, amada prima, en una de aquellas noches hermoseadas con la luna apacible de nuestra cara pátria; a

16 GÓMEZ DE AVELLANEDA, Gertrudis. Memorias inéditas de la Avellaneda, p.2.

17 GÓMEZ DE AVELLANEDA, Gertrudis. Memorias inéditas de la Avellaneda, p.2.

18 A canção foi composta pelo francês Frédéric Bérat (1801-1855). Avellaneda modifica levemente os versos finais da canção.

19 GÓMEZ DE AVELLANEDA, Gertrudis. Memorias inéditas de la Avellaneda, p.3. 
tu lado, en una pequeña y escojida reunión de amigos, rodeadas de tus amables hermanas, y mirando a nuestras dos madres gozar con entusiasmo maternal de nuestros juegos o conversaciones, y refiriendose, con aquella confianza de una amistade de 40 años, sus pequeños negocios domésticos! (...) Todo, todo se pasó... todo se há mudado! Yo sali llena de ilusiones a ver mundo (...) ya he visto bastante pero he perdido todas mis ilusiones. En aquellos tiempos que nada habia visto fuera de mi país natal, yo creaba otros mundos en mi imaginación, ahora no tengo más que uno (...) está delante de mi, lo veo, con todos sus prestigios, con todas sus brillantes miserias (...) y sin embargo, el vacío del corazón está todavia (...) no le llenan ahora ni aun las ilusiones... siempre este vacío! Siempre! 20

O sentimento de dor em relação à distância da pátria também pode ser identificado numa visita realizada ao cemitério de La Coruña, quando se vê diante da lápide de um general inglês ali sepultado e afirma: "no me retiré de aquel sitio sin decir con emoción este verso de un poeta moderno: 'Grata y blanda esta terra te sea/si es que puede serlo nunca jamás/tierra extranjera'". 21

Cuba também se encontra presente em seu relato por meio das comparações que estabelece entre seu país e os lugares visitados na Europa. As comparações trazem uma forte carga valorativa, havendo freqüente exaltação a Cuba. Em mais de uma situação refere-se ao clima, contrastando o inverno europeu ao "eterno verão" cubano. ${ }^{22}$ Da mesma maneira, afirma que, apesar de ter apreciado o tempo passado em Bordéus, "es menos profundo y dulce este recuerdo que los que conservo de mi pátria". Os momentos vividos em Cuba são caracterizados como "sueños dichosos de mi primera edad". ${ }^{23}$ Realiza outra comparação no trecho em que atravessa o rio Garona, em direção a Bordéus, destacando a prodigalidade da natureza cubana, mas sem chegar a descartar o encanto produzido pela paisagem européia:

Yo había visto en Cuba sus soberbios montes, sus campos vírgenes coronados de palmas y caobas; había estendido la vista por sus inmensas sabanas y detenídola en sus ricos plantios (...) Sin embargo, me encantaron las campiñas deliciosas que adornan las márgenes soberbias del Garona. ${ }^{24}$

Sobre as noites de La Coruña, afirmava sentir a predominância de "un aire de tristeza y languidez", conseqüência da falta do "alegre ruído" pro-

20 GÓMEZ DE AVELLANEDA, Gertrudis. Memorias inéditas de la Avellaneda, p.10.

21 GÓMEZ DE AVELLANEDA, Gertrudis. Memorias inéditas de la Avellaneda, p.15.

22 GÓMEZ DE AVELLANEDA, Gertrudis. Memorias inéditas de la Avellaneda, p.24 e 25

23 GÓMEZ DE AVELLANEDA, Gertrudis. Memorias inéditas de la Avellaneda, p.6.

24 GÓMEZ DE AVELLANEDA, Gertrudis. Memorias inéditas de la Avellaneda, p.5. 
vocado pelo trânsito das carruagens, a que seu ouvido estava acostumado em Cuba. ${ }^{25}$

Pretendemos assinalar, até aqui, a presença marcante de Cuba neste primeiro relato de Avellaneda, mostrando que ela se dá, seja por meio da retórica romântica do exílio, seja pelas freqüentes comparações que destacam aspectos positivos da ilha.

É verdade que a autora não contrastou ou aproximou comparativamente somente Cuba e a Europa, mas estabeleceu também comparações entre as diferentes cidades que conheceu em sua viagem. Ainda é preciso lembrar que este relato tinha como destinatária sua prima cubana, e que, além disso, havia pouco tempo que a autora chegara à Europa, podendose cogitar, assim, ser "natural" a existência de constantes referências a sua terra de origem. Apesar destas advertências explicarem, em parte, a forte presença das referências a Cuba, é impossível deixar de se notar o absoluto contraste existente, neste sentido, entre o primeiro e o segundo relato de viagem de Avellaneda.

Em Mi última excursión por los Pirineos, datado de 1859 e produzido, portanto, mais de duas décadas depois de partir de Cuba, o lamento da distância da terra natal desaparece, e a retórica romântica do exílio se constrói apenas através do tema do refúgio em meio à natureza. À diferença do primeiro relato, em nenhum momento a autora se refere à paisagem cubana. Avellaneda se preocupa em retratar somente o cenário europeu, procurando traduzir as sensações despertadas pelo contato com a natureza. ${ }^{26}$

Nota-se, principalmente na parte em que descreve as excursões pelos Pirineus franceses, que buscava encontrar os pontos onde a vista era mais apropriada para o vislumbre da paisagem natural. Em Pau, ao se encontrar

25 GÓMEZ DE AVELLANEDA, Gertrudis. Memorias inéditas de la Avellaneda, p.14.

26 A maneira como Avellaneda interpreta a natureza traduz um comportamento que se tornou comum entre viajantes, intelectuais e, sobretudo, entre os escritores ligados ao romantismo. Afirma-se que, a partir do século XVIII, processou-se uma idealização da vida campestre e, por extensão, uma valorização da natureza. Em certa medida, este comportamento se opunha ao ideal renascentista, pelo qual a cidade era entendida como lugar onde o homem teria acesso ao aprendizado e à sofisticação, ao contrário do campo, que manteria o homem mergulhado na rusticidade. A Revolução Industrial e o papel central das cidades neste processo (cujo ritmo de vida diferiria cada vez mais daquele vivenciado no campo) são apontados como fatores que teriam contribuído para a idealização da vida campestre e da natureza. Como frutos dessa valorização, diferentes formas de expressões artísticas, como a literatura e a pintura, passaram a representar os desejos de se viver os "prazeres rurais" e os "atrativos espirituais e estéticos do campo". Neste século e no seguinte, passaria a preponderar ainda uma tendência a se valorizar, para além da vida campestre, a natureza em seu estado primitivo, selvagem, ideal este que também se atrela ao processo de desenvolvimento industrial europeu. A natureza passaria, assim, a ser cada vez mais procurada por viajantes e escritores, que sobre ela comporiam suas descrições. Considerada como um objeto de fruição estética, encontrava-se nela a beleza, que não era suscitada, então, apenas pelas paisagens que sugeriam tranqüilidade e harmonia, mas pelo terrífico, pelo sublime, vivenciado nos locais e situações onde a natureza mostrava toda a sua pujança como, por exemplo, nas mais altas montanhas. THOMAS, Keith. 0 homem e o mundo natural: mudanças de atitudes em relação às plantas e aos animais (1500-1800). São Paulo: Companhia das Letras, 1988, p.95. STAROBINSKI, Jean. A invenção da liberdade, 1700-1789. São Paulo: Editora da Universidade Estadual Paulista, 1994, p.181. Para uma interpretação sobre este tipo de visão da natureza nas representações de pintores norteamericanos do século XIX, ver: PRADO, Maria Ligia Coelho. Natureza e identidade nacional nas Américas. In: América Latina no século XIX: tramas, telas e textos. São Paulo: Edusp, 1999. Sobre o hábito de escalar montanhas a partir do século XVIII, ver também CLARK, Kenneth. Civilização: uma visão pessoal. São Paulo: Martins Fontes, 1995, p.291. 
em uma esplanada que the propiciava ampla visão, afirma poder gozar ali, "uno de los más notables puntos de vista de los muchos que ofrece aquel país incomparable". Daquele lugar, apreciava

cadenas de colinas que se despliegan escalonadas con su espléndido manto de verdura; los Pirineos dibujando al fondo sus azulados contornos, que parecen a la pálida luz de la tarde caprichosos grupos de fantasmas; el pico de Ossau levantándose como un gigante de entre aquellas indefinidas sombras (...) todo es allí sorprendente, pintoresco, magnífico. ${ }^{27}$

Em diferentes momentos, destaca os esforços que eram necessários para se atingir um determinado local onde a vista era privilegiada. $\mathrm{O}$ espetáculo da natureza e a fruição da paisagem, entretanto, compensavam todos os desgastes físicos e perigos, como aponta na descrição de suas excursões nos arredores de Gavarnie:

No esperen (...), mis amigos, que intente describirles el espectáculo que la na-
turaleza presentó a mis miradas, no; vayan a contemplarlo si tienen corazón, si
sienten vibrar en su alma la cuerda armoniosa que responde a todo lo bello, a
lo sublime. Tiendrán que afrontar dificultades y fadigas, es cierto; tendrán que
seguir angostos desfiladeros, sendas que serpentean por los flancos de la cor-
dillera suspendidos sobre abismos en cuyo fondo se oye mugir incesantemente
el Gave Bearnés que va socavando los robustos cimientos de las montañas que
comprimen su lecho; palidecerán alguna vez, por valientes que sean, al verse
como sepultados bajo inmensas bóvedas de colosales peñascos que amenazan
desplomarse sobre sus cabezas (...) Pero en cambio de estos peligros - que
no carecen de halago para los espíritus aventureros icuántas impresiones les
guardan aquellos lugares que ningún pincel, que ninguna pluma acertará nunca
describir!?

Mesmo quando descreve a paisagem das vilas e cidades dos Pirineus, destaca a presença da natureza. Em Cauterets, por exemplo, encontra modernos hotéis, salões de reunião, gabinetes de leitura, cafés, animação e movimento. Entretanto, assegura que ali podia desfrutar, ao mesmo tempo, dos "goces refinados de la sociedad y los sencillos del campo", pois a vila se encontra como que encravada na natureza. ${ }^{29}$

$\mathrm{Na}$ formulação de uma visão valorativa da natureza, Avellaneda cria uma oposição entre um idílico ambiente natural, onde o homem pode sentir a presença divina, e a vida nas cidades, nas quais predominam os interesses mundanos. É justamente diante da vista das montanhas dos Pirineus que Avellaneda realiza suas mais inspiradas descrições. No Pico do Meio Dia, que alcança cerca de três mil metros de altitude, por onde

27 GÓMEZ DE AVELLANEDA, Gertrudis. Mi última excursión por los Pirineos, Diário de la Marina, p.17.

28 GÓMEZ DE AVELLANEDA, Gertrudis. Mi última excursión por los Pirineos, Diário de la Marina, p.24-25.

29 GÓMEZ DE AVELLANEDA, Gertrudis. Mi última excursión por los Pirineos, Diário de la Marina, p.23. 
chegou partindo de Bigorre, nos Pirineus franceses, afirma que a solidão das grandiosas alturas desperta o caráter filosófico do homem, por menos pensador que este se pretenda. O ser humano, ali, se desprende das "risibles pompas", das "convenciones sociales", das "mezquinas pasiones" e dos "frívolos intereses" das cidades, "aquellos hormigueros humanos que vemos a nuestros pies". Além disso, as montanhas suscitam, naturalmente, nos homens, o sentimento religioso, uma vez que "el infinito se les revela de manera más sensible, más continua que a los que sólo ven el cielo desde terrenos bajos". ${ }^{30}$ Na descrição do Circo de Gavarnie - depressão em meio a um maciço montanhoso onde se encontram elevadas paredes calcárias, além da maior cascata da Europa -, sente a presença divina, bem como identifica a permanência, a não transformação do mundo pela mão humana. Ali, segundo Avellaneda, a paisagem se mantivera intacta, tal como havia sido construída desde o início dos tempos. Nem mesmo a existência de ruínas, que indicam a presença humana, é capaz de retirar o caráter primitivo e agreste daquela paisagem, o que revela a impotência humana diante da grandiosidade do poder divino. ${ }^{31}$

Procuramos mostrar que em seu relato sobre os Pirineus, Avellaneda privilegia o cenário europeu. Neste texto não encontramos sequer uma menção a Cuba. Há que se lembrar que, embora tenha publicado seu relato em Havana, Avellaneda o concebeu tendo como objetivo descrever a região dos Pirineus franceses para seus amigos espanhóis. São estes, portanto, os seus interlocutores imediatos. ${ }^{32}$ No entanto, mais do que simplesmente dialogar com os espanhóis, Avellaneda chega a se incluir entre eles, assumindo uma identidade espanhola:

Tres días hacía apenas que nos hallábamos asociados a los doce o quince personas de la excursión a Gavarnie, y en tan corto número de horas reinaba ya entre todos, no esa intimidad de confianza afectuosa a que somos propensos los españoles, pero sí la armonía de gusto, de comunion de impresiones, la recíproca necesidad de agradarnos, que ahuyentando contrariedades contribuían poderosamente a prestar encantos a nuestra expedición, y a hacernos sentir penosamente su término próximo. ${ }^{33}$

Aqui é interessante notar um outro aspecto de suas observações. Por um lado, como afirmamos, ela se inclui entre os espanhóis, no diálogo estabelecido, por via do relato, com seus amigos peninsulares. Por outro, situa a heterogeneidade do grupo que a acompanhava em suas excursões, formado por espanhóis, franceses e ingleses. Nos seus comentários, a au-

30 GÓMEZ DE AVELLANEDA, Gertrudis. Mi última excursión por los Pirineos, Diário de la Marina, p.41.

31 GÓMEZ DE AVELLANEDA, Gertrudis. Mi última excursión por los Pirineos, Diário de la Marina, p.25-26.

32 GÓMEZ DE AVELLANEDA, Gertrudis. Mi última excursión por los Pirineos, Diário de la Marina, p.15.

33 GÓMEZ DE AVELLANEDA, Gertrudis. Mi última excursión por los Pirineos, Diário de la Marina, p.26 (Grifos nossos) 
tora aproxima espanhóis e franceses, ao mesmo tempo em que estabelece um distanciamento em relação aos ingleses. Eis suas apreciações sobre os companheiros de viagem franceses:

No hay compañeros de viaje como los franceses: entusiastas, penetrantes, inteligentes, cosmopolitas por instinto y por educación, y poseedores de ese tacto exquisito que aprecia y comprende todos los caprichos del sentimiento y de la imaginación, ellos no se quejan nunca de las molestias de una penosa marcha, que saben amenizar con su verboso sprit; ellos gozan de todo con expansión ardiente, se comunican a la vez que son partícipes de las ajenas impresiones. ${ }^{34}$

Em contrapartida, afirma sobre os três ingleses que integravam o grupo:

Contrastando con la identidad de deseos y de intereses que unía ya a los indivíduos de ambos sexos que visitábamos gustosos a Gavarnie, iban trés ingleses, y aunque formaban parte de la caravana, no podía decirse con exactitud fuesen de la compañía, pues se conservaban constantemente desviados de ella y ajenos a todas sus impresiones. Aquellos hombres, que casualmente venían desde Bayona siguiendo el itinerario nuestro, hospedandose en los mismos hoteles que nosotros, y de Cauterets a Saint-Saveur hasta ocupando asientos en el mismo carruage que nos conducía, no habian, sin embargo, trocado con mi marido ni conmigo una sola palabra de urbanidad, un mero saludo silencioso. (...) Los tres hijos de Albión formaban siempre grupo aparte: jamás emitían un parecer, ni aventuraban una observación, ni mostraban con una mirada siquiera ser partícipes de nuestros temores y placeres. Iban en la animada expedición como las maletas del equipaje, mudos, impacibles, cual en movimiento involuntario a cuyos accidentes no eran accesibles. ${ }^{35}$

Até o final do relato, Avellaneda segue tecendo considerações sobre os ingleses. A despeito do tom bem humorado e espirituoso empregado em sua caracterização, são, em geral, descritos como seres taciturnos, calados e sombrios, além de se manterem, de acordo com a autora, sempre afastados do restante dos viajantes, que interagiam socialmente entre si. ${ }^{36}$

34 GÓMEZ DE AVELLANEDA, Gertrudis. Mi última excursión por los Pirineos, Diário de la Marina, p.26.

35 GÓMEZ DE AVELLANEDA, Gertrudis. Mi última excursión por los Pirineos, Diário de la Marina, p.26-27.

36 GÓMEZ DE AVELLANEDA, Gertrudis. Mi última excursión por los Pirineos, Diário de la Marina, p.37-38. Tais apreciações de Avellaneda em relação aos ingleses, de um lado, e franceses e espanhóis, de outro, podem ser entendidas como parte das representações criadas sobre os latinos e anglo-saxões no século XIX, que alcançam repercussão no contexto do Império de Napoleão III. Na primeira metade do século XIX, Michel Chevalier produziu idéias que dariam sustentação às pretensões imperialistas do Segundo Império francês. O autor defendia a existência de rivalidades entre ramos da civilização ocidental: de um lado estavam os latinos ou romanos, de religião católica, entre os quais a França se destacaria como a primeira das nações; de outro, se encontrava a "raça germânica", dentre os quais incluíam-se os anglo-saxões, que professavam o protestantismo como prática religiosa. A dicotomia "saxões versus latinos" foi empregada politicamente para legitimar as pretensões francesas sobre a América de colonização espanhola, apelando-se a um projeto de unidade dos povos latinos; ao mesmo tempo, representava uma forma da França tentar barrar as projeções de expansão dos Estados Unidos (país que seria portador do legado anglo-saxão) sobre o continente americano. Em meados do século, a corrente do "panlatinismo" já teria popularizado a versão que encontraria, posteriormente, mais adeptos, inclusive na América Latina, segundo a qual os povos latinos seriam portadores de uma "superioridad espiritualista o idealista", contraposta a 
Comparando os dois relatos de viagem de Avellaneda, observamos uma relação diferenciada da autora no que diz respeito à questão da afirmação de sua identidade. No primeiro, declara fortemente sua ligação com Cuba; no segundo, afirma-se como espanhola. Como já lembramos anteriormente, há diferenças nas condições de produção destes dois textos. Quando escreveu seu primeiro relato, havia pouco tempo que saíra de Cuba e, além disso, tinha como interlocutora imediata sua prima cubana. O segundo relato, ao contrário, foi produzido depois de viver mais de duas décadas na Espanha, tendo este sido composto, inicialmente, para amigos espanhóis.

Levando em consideração apenas tais evidências, poder-se-ia deduzir que a vivência de duas décadas na Espanha teria resultado na substituição de sua identidade cubana pela espanhola. Entretanto, analisando várias circunstâncias, parece ser mais correto discutir a questão em termos da presença de uma ambivalência identitária que marca seu discurso e sua prática, como mostram suas tentativas de participar dos cânones literários tanto cubano como espanhol.

Em seus escritos, Cuba aparece como fonte de exaltação patriótica, como nos sonetos Al Partir e La vuelta a la Pátria, ou mesmo em seu primeiro relato de viagem. Ao mesmo tempo, a paisagem cubana e as questões sociais da ilha, como a escravidão, marcam seu romance Sab. Por outro lado, em diferentes textos, procura mostrar a existência de vínculos com a Espanha, como em uma de suas autobiografias, na qual evoca a origem espanhola paterna. O desejo de seu pai de rever sua terra natal gerava na autora um "entusiasmo por el hermoso país de sus ascendientes". A Espanha teria sido desde muito cedo, para Avellaneda, também fonte de inspiração literária: "Aún no tenía nueve años y ya escribía apasionados versos, que tenían por objeto las amenas orillas del Guadalquivir y las hazañas de mis abuelos en aquellas regiones afortunadas, donde yo imaginaba reunido todo lo grande y todo lo bello que existe en el universo". ${ }^{37}$

Além de se inspirar nas temáticas e cenário europeus para a produção de diferentes obras, considerava-se como parte da literatura e dramaturgia espanholas. Em abril de 1852, escreveu uma carta a Manuel Cañete, que fora diretor de La Aureola, de Cádiz - do qual Avellaneda tinha sido colaboradora -, e então dirigia El Heraldo. Nela, pedia a opinião do periodista sobre sua intenção de dedicar sua comédia dramática, Errores del Corazón, a Luis José Sartorius, o conde de San Luís, figura politicamente atuante no

um espírito "pragmático o empirista", pelo qual os anglo-saxões eram caracterizados. QUIJADA, Mónica. Sobre el origen y difusión del nombre 'América Latina' (o una variación heterodoxa en torno al tema de la construcción social de la verdad). Revista de Indias, Espanha, CSIC, v.LVIII, nº.214, p.599, 1998. FUNES, Patricia. Del Mundus Novus al Novomundismo. Algunas reflexiones sobre el nombre de América Latina. In: DAYRELL, Eliane Garcindo e IOKOI, Zilda Gricoli. (Orgs.) América Latina contemporânea: desafios e perspectivas. São Paulo/Rio de Janeiro: Edusp/Expressão e Cultura, 1996, p.82.

37 Cf. sua última autobiografia, publicada em 1850 em La llustración, de Madri. Citado por: COTARELO Y MORI, Emilio. La Avellaneda y sus obras, p.15-16. 
reinado de Isabel II. Tinha em mente cumprir dois objetivos com a dedicatória: além de agradecer o empenho de Sartorius por ter colocado em cena sua tragédia bíblica Saul, pretendia homenageá-lo pela fundação do Teatro Espanhol, um ato, segundo a autora, feito "en bien de nuestra pobre literatura dramática". ${ }^{38}$

Correspondente a esta ambivalência identitária presente em seu discurso é a forma como a autora figurou em diferentes episódios na Espanha e em Cuba. Avellaneda pretendeu fazer parte tanto do cânone literário espanhol como do cubano. Envolveu-se em intensa - e frustrada - luta visando ser aceita como membro da Real Academia Espanhola, em 1853. Pretendia ocupar o lugar de Juan Nicasio Gallego, morto pouco tempo antes, alegando ser desejo do poeta que ela o sucedesse em sua cadeira. ${ }^{39}$ Por outro lado, reagiu fortemente, mais de uma década depois, a uma tentativa de alguns intelectuais cubanos de excluí-la da literatura cubana. O episódio ocorreu em 1867 e teve por liderança o poeta José Fornaris, idealizador de uma coletânea de poemas de autores cubanos, intitulada La Lira Cubana. Segundo Fornaris, as obras de Avellaneda não deveriam ser integradas à antologia, uma vez que a considerava não como uma autora cubana, mas sim como "escritora madrilenha". ${ }^{40}$

Avellaneda reagiu à sua exclusão da Lira Cubana. Demonstrações desta reação são duas cartas que fez publicar, respectivamente em 1867 e 1868, em periódicos cubanos como El Fanal e El Siglo. Este último havia publicado a notícia de sua exclusão da antologia. Nas duas cartas, que possuem, com poucas diferenças, o mesmo conteúdo, Avellaneda afirma que aceitaria sua exclusão se esta tivesse como explicação a contestação da qualidade literária de sua obra e não o argumento utilizado pelos organizadores da antologia de que a autora não era cubana. Reage firmemente às acusações de que não era "cubana de corazón" ou de que seria "hija desnaturalizada del país a quien tanto debo". ${ }^{41}$

Diante disso, vários cubanos se posicionaram a favor de Avellaneda. Dentre as manifestações de apoio destacam-se as da Seção de Literatura do Liceu de Havana, do periódico Aurora del Yumurí e da periodista e tipógrafa Domitila García de Coronado. ${ }^{42}$

38 Citado por COTARELO Y MORI, Emilio. La Avellaneda y sus obras, p.223 (Grifo nosso)

39 COTARELO Y MORI, Emilio. La Avellaneda y sus obras, nota 1, p.244.

40 ESCOTO, José Augusto. (org.) Gertrudis Gómez de Avellaneda. Cartas inéditas y documentos relativos a su vida em Cuba de 1859 a 1864. Matanzas: Imprenta Pluma de Oro, 1911, p.10-11. José Fornaris havia publicado, em 1855, o livro intitulado Cantos del Siboney, que deu origem ao chamado "siboneyismo", vertente literária inscrita na corrente indianista, que pretendia criar uma poesia nacional recuperando, para isso, o mundo dos primeiros habitantes de Cuba, aniquilados pela conquista espanhola.

41 Da versão publicada em EI Siglo, em 1868. Citado por ESCOTO, José Augusto. (org.) Gertrudis Gómez de Avellaneda. Cartas inéditas y documentos relativos a su vida em Cuba de 1859 a 1864. Matanzas: Imprenta Pluma de Oro, 1911, p.177.

42 ESCOTO, José Augusto. (org.) Gertrudis Gómez de Avellaneda, p.62-64; 177. 
Não podemos deixar de lembrar que este debate sobre a "cubanidade"/ "hispanidade" de Avellaneda se dava às vésperas do início de um grande movimento em prol da independência de Cuba, a chamada Guerra Grande, que se estendeu de 1868 a 1878 e que findou com a derrota dos rebeldes pelos peninsulares. Dela resultou um pacto pelo qual, embora oficialmente a Espanha se comprometesse a efetuar reformas e garantir maior autonomia à ilha, se mantinha o estatuto colonial. ${ }^{43}$

Durante sua vida na Espanha, Avellaneda manteve íntimas relações com a corte. Vale lembrar que, quando partiu da Espanha em direção a Cuba, em 1859, foi declarada porta-voz de Isabel II na tarefa de transmitir aos cubanos "lo mucho que los estimaba, y que no perdía la esperanza de visitarlos algun dia". ${ }^{4}$ Há autores que ressaltam sua proximidade em relação ao poder espanhol e até uma adesão à monarquia; outros afirmam que ela aliava "principios progresistas del liberalismo" com a monarquia. De qualquer maneira, diferiria de intelectuais claramente comprometidos com a causa da independência. ${ }^{45}$

Cabe aqui retomar algumas idéias de Enrico Mario Santí sobre a questão da construção da identidade nacional cubana. Para o autor, em Cuba, os escritos de diferentes intelectuais mostram que uma consciência de identidade cubana começa a ser forjada desde o início do século XIX. Entre eles se encontrava José Antonio Saco, para quem "negar la nacionalidad cubana es negar la luz del sol de los trópicos en punto de mediodía". 46 Para Santí, o processo de formação de uma identidade nacional cubana na primeira metade do século XIX, que envolveu atores comprometidos com a questão da independência, preparou o caminho para a guerra iniciada em 1868, e esta teria um papel decisivo na insurreição contra a Espanha a partir de 1895. ${ }^{47}$ Desde o início do século XIX, a questão da "invenção da nação", segundo o autor, pressupunha o enfrentamento do problema da independência política em relação à Espanha. Ambos os aspectos - a forja da nação e a independência - andavam de mãos atadas:

Cuba fue, durante la mayor parte del siglo XIX, una sociedad traumatizada por la institución de la esclavitud. Pero el problema social aún mayor que encaraba la isla, para los cubanos de todas las razas, incluyendo desde luego a su minoría blanca, era la libertad a secas, y específicamente la independencia politica de España. Fueron las transacciones culturales, tanto reales como imaginarias, entre

43 Seria preciso esperar até o ano de 1898 para que se visse declarada a independência de Cuba, realizada com a interferência dos Estados Unidos que se colocaram em guerra contra a Espanha, tendo em vista os interesses intervencionistas norte-americanos na América Latina.

44 Conforme noticiado no periódico madrilenho El Estado e reproduzido em Cuba em Aurora del Yumurí, de 23/11/1859. Citado por ESCOTO, José Augusto. (org.) Gertrudis Gómez de Avellaneda, p.109 e COTARELO Y MORI, Emílio. La Avellaneda y sus obras, p.345.

45 A primeira posição é defendida por COTARELO y MORI; a segunda por ESCOTO

46 Citado por SANTí, Enrico Mario. Nación inventada, p.26.

47 SANTí, Enrico Mario. Nación inventada, p.22. 
blancos y negros, criollos y españoles, las que por tanto vertebraron la larga e intensa lucha política entre isla y metrópoli. En la lucha por esa independencia, que de hecho no se realizó hasta el siguiente siglo, los cubanos del XIX inventaron a su nación. Fue esa invención la que le dio justificación moral a su lucha separatista, la que le concedió al pueblo una identidad colectiva, y la que forjó gran parte de la mitología cultural con la que los cubanos se representan a sí mismos hasta hoy. La "búsqueda de la libertad" (...) le da contenido a esa invención; y a su vez, la invención de la nación cubana le da forma a ese contenido, el cual incluye los valores de soberania nacional e identidad autónoma. ${ }^{48}$

Se levarmos em consideração essa interpretação, podemos concluir que Avellaneda participou da construção de uma idéia de nacionalidade cubana, mas que as ambigüidades de suas opiniões sobre a manutenção do poder espanhol e as ambivalências na afirmação de sua identidade, alimentaram os questionamentos de outrem em relação a sua real identificação com Cuba. Avellaneda entrava, assim, no rol dos escritores que expressavam a existência de uma identidade cubana, mas ao mesmo tempo era distanciada deles na medida em que não se mostrava claramente adepta da independência de Cuba. Da maneira como a nação cubana foi forjada, intrinsecamente associada ao problema da emancipação, o atestado de uma "verdadeira" identificação com a nação passaria, sobretudo num contexto de guerra aberta contra a metrópole, pela declaração aberta de apoio à independência cubana, ficando vulneráveis a questionamentos os atores que manifestassem ambigüidades políticas em relação à manutenção ou rompimento do status colonial.

Como afirmamos, Avellaneda se declarou, ao mesmo tempo, espanhola e cubana, da mesma maneira que pretendeu se inserir nas tradições literárias da península e da ilha. Entre os seus contemporâneos, encontramos expressões favoráveis a diferentes opiniões. Havia os que a colocavam como parte da literatura espanhola: vários exemplos estão disponíveis na imprensa da época que comentava suas peças de teatro, o mesmo valendo para os obituários em jornais espanhóis à época de sua morte, que lastimavam a grande perda para a "literatura espanhola". ${ }^{49}$ Outros defendiam sua identidade cubana, como já foi mostrado anteriormente. Alguns ressaltavam sua participação tanto na literatura espanhola como na cubana. O escritor espanhol José Zorrilla, em seu livro de memórias, Recuerdos del tiempo viejo (1881), alude à origem cubana de Avellaneda e, ao mesmo tempo, ao pertencimento da autora à literatura espanhola. Ao rememorar o dia em que introduziu Avellaneda no Liceu de Madri, declara que uma vez apresentada por ele, "quedó aceptada en el Liceo y, por consiguinte, en Madrid como la primera poetisa de España, la hermosa cubana Gertrudis

48 SANTÍ, Enrico Mario. Nación inventada, p.26.

49 COTARELO Y MORI, Emílio. La Avellaneda y sus obras, p.190, 230, 234, 372 e 373. 
Gómez de Avellaneda". ${ }^{50}$ Por fim, outros a classificavam como "escritora universal". Dois escritores espanhóis apontam nesta direção: Juan Valera, para quem Avellaneda atingiu uma glória universal, e Nicomedes Pastor Díaz, que afirmava: "Avellaneda tiene por pátria a su siglo, aunque el lugar de su cuna haya sido la zona ardiente de las Antillas. Fueron sus padres Herrera y Rioja, Quintana y Heredia, Calderón, Corneille y Racine, Byron y Chateaubriand, Schiller y Walter Scott". ${ }^{51}$

Em Cuba, além da polêmica já apontada, o questionamento dos vínculos de Avellaneda com a América e sua ligação com a Europa foram abordados ainda por José Martí, que comparou a autora com a poetisa cubana Luisa Pérez Zambrana. Martí elege Zambrana "mejor poetisa americana" do que Avellaneda. ${ }^{2}$

A polêmica teve prolongamentos no século XX. Na década de 1940, foi tema de um debate publicado em duas revistas populares de Cuba, Bohemia e Carteles, entre o periodista Antonio Martínez Bello e o diplomata José de La Luz León, que sustentavam opiniões opostas. No julgamento de José de La Luz Leon, publicado na primeira revista, o sentimento de amor à pátria, expresso por Avellaneda, não teria sido sincero, mas "postizo, transitorio, de mera ocasión..., lírico, es decir, verbal, externo, imaginado". Em resposta, Martínez Bello tentou comprovar, na edição de 31 de agosto de 1947, de Carteles, a real ligação identitária da autora com Cuba, apesar de não negar os estreitos vínculos com a Espanha. De acordo com o autor, Cuba e Espanha não seriam antíteses, para Avellaneda, mas sim, "armoniosa y fecunda síntesis". Também contesta a idéia de que o sentimento que expressava por Cuba era "postiço" e "transitório". Ao contrário, para ele a autora era "sincera, cordial, consciente; expresiva de algo propio y hondo de su personalidad, cuando canta su amor a Cuba y la llama claramente de 'patria' suya". O autor elenca algumas justificativas - em boa medida preconceituosas - visando mostrar porque Avellaneda não teria se engajado mais em causas cubanas: por ser rica, criada em lar espanhol e em ambiente reacionário às idéias emancipacionistas; além disso, porque era mulher: por essa "predeterminación ambiental, no podía en modo alguno tener tan exacta y entrañable noción de la realidad cubana ni de sus tendencias profundas e inaplazables". Por isso seu "amor nativo" teve uma "condición no militante", e seu protesto a favor da liberdade "tuvo mucho de protesta platónica". Entretanto, para o autor, isso não significa que Avellaneda não

50 Citado por COTARELO Y MORI, Emílio. La Avellaneda y sus obras, p.70. (Grifos nossos)

51 VALERA, Juan. Florilegio de poesias castellanas del siglo XIX. Madrid, 1902, T.1, p.127-128. Cit. ESCOTO, José Augusto (org.). Gertrudis Gómez de Avellaneda, p.228.; PASTOR DÍAZ, Nicomedes. Noticia biografica de la AveIlaneda. In: GÓMEZ DE AVELLANEDA, Gertrudis. Obras, T.1, p. XVII. Cit. ESCOTO, José Augusto (org.). Gertrudis Gómez de Avellaneda, p.225.

52 MARTÍ, José. Obras 1900-1915 Edição de Gonzalo de Quesada. Vol. 13, p.96-99. Reproduzido em http://www. damisela.com/literatura/pais/cuba/autores/marti/proceres/zambrana.htm 
expressasse sua identidade cubana: "no por falta de versión beligerante, dejó de ser sincero y real su amor a Cuba". ${ }^{53}$

A questão teve também repercussões na crítica literária no século XX. Segundo Pedro Henríquez-Ureña, Avellaneda, a despeito de ter-se mudado jovem para a Espanha, sempre manteve uma forte relação com a ilha. O autor faz esta afirmação confrontando a posição de Avellaneda com a de outros autores, para ele definitivamente "transplantados", os quais se desvincularam definitivamente de seus países de origem. Para o crítico, é revelador da manutenção da identidade cubana da autora o fato de ter saído tão jovem da ilha e de ter sustentado esta conexão mesmo quando Avellaneda estava no auge de sua carreira literária, momento este, inclusive, que coincide com o retorno a Cuba, em $1860 .{ }^{54}$ Por outro lado, em uma nota de seu livro, afirma que Avellaneda é considerada tanto uma autora pertencente à tradição literária americana quanto à européia, fato que considera raro entre os seus contemporâneos. ${ }^{55}$

Em Cuba, o poeta e crítico Cintio Vitier, em seu livro Lo cubano en la poesia (1958), põe em dúvida a capacidade de Avellaneda de traduzir o caráter cubano. Afirma não encontrar nela

una captación íntima, por humilde que sea, de lo cubano en la naturaleza o en el alma; ni una voz que nos toque las fibras ocultas. Gallarda y criolla si; (...) pero cubana de adentro, de los adentros de la sensibilidad, la magia y el aire, que es lo que andamos buscando? confieso llanamente mi impresión: no encuentro en ella ese registro. ${ }^{56}$

Em 1973, o crítico literário José Antonio Portuondo publicou um ensaio apontando a neutralidade e falta de compromisso da autora com a causa da independência. ${ }^{57}$

Atualmente, estes julgamentos vêm sendo questionados, sobretudo pela crítica feminista, que os interpreta, numa chave analítica diferenciada, como uma conseqüência de predeterminações derivadas de preconceitos de gênero. Reivindica-se, assim, ao mesmo tempo, a recuperação do legado de mulheres escritoras latino-americanas, bem como as contribuições das mesmas nos discursos nacionais emergentes do século XIX. Destaca-se, neste sentido, a análise de Adriana Méndez-Rodenas, na qual o discurso

53 MARTínEZ BELLO, Antonio. La cubanidad de Avellaneda. In: Carteles, 31 de agosto de 1947.

54 HENRÍQUEZ-URENA, Pedro. Literary currents in Hispanic America. Cambridge/Massachusetts: Harvard University Press, 1945, p.123.

55 HENRÍQUEZ-UREÑA, Pedro. Literary currents in Hispanic America, nota 24, p.246.

56 VITIER, Cintio. Lo cubano en la poesía. La Habana: Universidad Central de las Villas, 1958. Cit. ALBíN, María C Género, poesía y esfera pública. Gertrudis Gómez De Avellaneda Y La Tradición Romántica. Madrid: Editorial Trotta, 2002, p.79.

57 Cf MENDEZ-RODENAS, Adriana. Mujer, nación, y otredad en Gertrudis Gómez de Avellaneda. In: Cuba en su imagen: historia e identidad en la literatura cubana. Madrid: Editora Verbum, 2002, p.27. O texto a que a autora se refere é: PORTUONDO, José Antonio. La dramática neutralidad de Gertrudis Gómez de Avellaneda. Revolución y Cultura, La Habana, nº.11, 1973. 
feminino é interpretado a partir da associação entre a representação da mulher e outros grupos sociais. Para esta autora, o romance abolicionista de Avellaneda, Sab, forja "un discurso híbrido de la marginalidad que enlaza el análisis de la condición social de la mujer con la representación del Otro, el negro esclavo, resultando en una visión más aguda y comprensiva de la nacionalidad cubana del momento". ${ }^{58}$ De acordo com Méndez-Ródenas, a análise da questão da identidade na ilha precisa levar em consideração o caráter transcultural da realidade cubana. Avellaneda, assim, participaria desta cultura ao "trasladar o transmutar el código romántico practicado en la península al escenário insular". ${ }^{9}$

Outros críticos literários também têm destacado a complexidade da análise do discurso de Avellaneda justamente pelo caráter paradoxal de suas formulações no tocante à representação da identidade nacional, e abandonando as antigas "acusações" sobre as identificações da autora com uma ou outra nação.

Em sua análise sobre Sab, Doris Sommer associa a condição de Avellaneda à do protagonista de seu romance: ambos representam o paradoxo, o novo, o diferente. Apesar das disputas existentes para classificá-la como cubana ou espanhola, Avellaneda não era, na acepção de Sommer, uma escritora do Novo nem do Velho Mundo: "Gertrudis era ambos, ou algo diferente; ela era Sab". ${ }^{60} \mathrm{Na}$ mesma direção, para a crítica literária portoriquenha, llia Casanova-Marengo, o mulato Sab, como personagem híbrido, que representa o novo e o inclassificável, condensa as ambivalências e incertezas próprias do caráter intersticial do discurso colonial. ${ }^{61}$ Como lembra Raúl lanes, já no início da década de 1840, Avellaneda adotou um pseudônimo - La Peregrina - que foi a forma utilizada para assinar suas primeiras publicações nos periódicos espanhóis. Segundo o autor, este pseudônimo revela, para além dos aspectos meramente biográficos, as condições culturais e históricas de que sua vida era permeada. O pseudônimo não denota exatamente a condição de "estrangeira na Península", uma vez que, nascendo na colônia, era uma "espanhola ultramarina". Por outro lado, não sendo "espanhola de nascimento", demarcava com este pseudônimo a particularidade de sua condição, informando, para seu público, sobre sua distante origem. Ainda de acordo com lanes, esta particularidade da condição da autora, traduzida em seu pseudônimo, indica uma "definición cultural esencialmente intersticial y por ende perturbadoramente integradora de la

58 MÉNDEZ-RODENA, Adriana. Mujer, nación, y otredad en Gertrudis Gómez de Avellaneda, p.16.

59 MÉNDEZ-RODENA, Adriana. Mujer, nación, y otredad en Gertrudis Gómez de Avellaneda, p.14.

60 SOMMER, D. Ficções de fundação. Os romances nacionais da América Latina. Belo Horizonte: Editora UFMG, 2004.

61 CASANOVA-MARENGO, Ilia. El interstício de la colonia. Ruptura y mediación en la narrativa antiesclavista cubana. Madrid: Iberoamericana; Frankfurt am Main: Vervuet, 2002. 
conflictiva dicotomía colonia-metropoli, isla-continente, América-Europa, propia de las circunstancias históricas y personales que le toca vivir". ${ }^{62}$

Os relatos de viagem de Avellaneda demonstram as diferentes posições assumidas pela autora em relação à questão da afirmação de sua identidade, mostrando mais fortemente sua ligação com Cuba no primeiro e com a Espanha no segundo. Apesar dos dois relatos se distanciarem temporalmente e de terem sido escritos para diferentes interlocutores, eles parecem refletir, não uma mudança de atitude de Avellaneda em relação aos seus vínculos com Cuba e a Espanha, mas, ao invés disso, uma ambivalência que se apresenta como uma constante em sua obra e trajetória.

A razão histórica para estas ambigüidades e polêmicas pode estar associada à tensão estabelecida entre: de um lado, um projeto desenvolvido em Cuba desde os primórdios do século XIX, por intelectuais comprometidos com a representação do nacional e com a independência; e de outro, a concreta situação política de manutenção do estatuto colonial. Este traço marca uma especificidade de Cuba no contexto político latino-americano. Nos diversos países da América Latina, os projetos de construção das identidades nacionais se desenvolveram em ambientes nos quais a independência política era já um dado da realidade, além de ocorrerem em paralelo ao processo de consolidação dos Estados nacionais, e como parte integrante deste mesmo processo.

A não declaração aberta de apoio à causa independentista cubana por parte de Avellaneda, bem como suas ligações com a Corte, possivelmente contribuíram para que, por um lado, se afirmassem suas tendências monárquicas, bem como se questionasse, por outro, sua identificação com Cuba, na medida em que a construção da idéia de nação se processava ao lado das tentativas de rompimento do estatuto colonial. Por esta razão, alguns de seus críticos por vezes caracterizaram seus versos alusivos a Cuba como mera retórica. Queriam dizer com isso que, para que seu discurso transcendesse à simples retórica, Ihe faltava um maior engajamento político.

Avellaneda foi colocada como peça chave num debate polêmico no campo das letras cubanas. As opiniões deste debate foram polarizadas, opondo aqueles que defendiam seus retratos de Cuba como reflexos do seu verdadeiro sentimento de amor à pátria, aos que afirmavam que seus versos não passavam de mera retórica. Os ecos deste debate ressoam ainda hoje, nas tentativas de combate à sua exclusão e de formulação de novas propostas analíticas que procuram realizar um cruzamento do discurso e atuações da autora com as particularidades do processo de afirmação nacional em Cuba.

62 IANES, Raúl. La esfericidad de papel. Gertrudis Gómez de Avellaneda, La Condesa de Merlin, y la literatura de viajes. Revista Iberoamericana, v. LXIII, ns. 178-179, p.210, enero-junio 1997. 